\title{
Affordable Care Act Qualified Health Plan Enrollment for AIDS Drug Assistance Program Clients: Virginia's Experience and Best Practices
}

\author{
Kathleen A. McManus, ${ }^{1}$ Robert C. Rodney, Anne Rhodes, ${ }^{3}$ Steven Bailey, and Rebecca Dillingham ${ }^{1}$
}

\begin{abstract}
With the implementation of the Affordable Care Act (ACA) in 2014, many safety net resources, including state AIDS Drug Assistance Programs (ADAPs), incorporated ACA Qualified Health Plans (QHPs) into their healthcare delivery model. This article highlights the benefits of the ACA for persons living with HIV. It also describes the range of strategies employed by state ADAPs to enroll patients in QHPs. The Virginia ADAP ACA implementation experience is described to illustrate one ADAP's shift to purchasing QHPs in addition to providing direct medications. Virginia ADAP is in a Medicaid nonexpansion state and funds the full costs of the QHP premiums, deductibles, and medication copayments. Virginia's experience is applicable to other Medicaid nonexpansion states and to state ADAPs in Medicaid expansion states, who are looking for options for their Medicaid ineligible clients. This article provides practical details of Virginia ADAP's ACA implementation as well as insights and best practices at both the state and clinic level.
\end{abstract}

$\mathbf{T}$ he Affordable Care Act (ACA) is a federal law that provides insurance coverage to previously uninsured people. People living with HIV (PLWH) are more likely to be uninsured than the general population and may benefit significantly from the availability of ACA Qualified Health Plans (QHPs). ${ }^{1-4}$ Not all states expanded Medicaid with the ACA, which has resulted in state safety nets, Ryan White clinics, and Ryan White-funded AIDS Drug Assistance Programs (ADAPs), working to insure their low-income patients. State ADAPs provide HIV medications to low-income PLWH. Most ADAPs incorporated the ACA into their model in some way. ${ }^{5}$ Nationally, ADAPs spent $\$ 2.01$ billion to provide medications to an estimated one-third of PLWH receiving care in $2013 .{ }^{6}$ Given the large size of this population, 210,000 ADAP enrollees in 2013, changes in healthcare delivery for the ADAP population can have broad reaching effects on engagement in care, access to antiretroviral therapy (ART), and viral suppression. ${ }^{6}$

Virginia has been a leader in incorporating the ACA into its ADAP healthcare delivery model by shifting from direct medication provision to supporting patient QHP enrollment.
During 2014 enrollment, Virginia ADAP clients accounted for $2 \%$ of ADAP clients nationwide, but they represented $17 \%$ of QHP-covered ADAP clients nationwide and 58\% of QHP-covered ADAP clients in southern states. ${ }^{7}$ Virginia's experience is applicable to Medicaid nonexpansion states as well as to Medicaid ineligible ADAP clients in Medicaid expansion states. This article will discuss benefits of the ACA for PLWH and the current national picture of state ADAPs incorporating the ACA. It will focus on Virginia ADAP's ACA implementation experience and provide some insights and best practices at both the state and clinic level to help other states and clinics in their assessment of and implementation of QHP enrollment for low-income PLWH.

\section{Benefits of the ACA to PLWH}

With the passage of the ACA in 2010, PLWH were able to sign up for preexisting condition insurance plans (PCIP) before the creation of Insurance Marketplaces. The Virginia ADAP supported patients' PCIP enrollment and paid patient premiums and cost shares. This early experience prepared both patients and the Virginia ADAP for the advent of QHPs, including how

\footnotetext{
${ }^{1}$ Division of Infectious Diseases and International Health, University of Virginia, Charlottesville, Virginia.

${ }^{2}$ University of Virginia Ryan White HIV Clinic, Charlottesville, Virginia.

${ }^{3}$ Virginia Department of Health, Richmond, Virginia.

(C) Kathleen A. McManus, et al., 2016; Published by Mary Ann Liebert, Inc. This Open Access article is distributed under the terms of the Creative Commons Attribution Noncommercial License (http://creativecommons.org/licenses/by-nc/4.0/) which permits any noncommercial use, distribution, and reproduction in any medium, provided the original author(s) and the source are credited.
} 
to navigate the paperwork and how to access medical care and prescriptions under federally subsidized insurance plans. PCIP was eliminated with the implementation of the ACA Marketplace QHPs, and PCIP patients became eligible for QHPs.

The ACA requires the availability of QHPs on ACA Health Insurance Marketplaces. QHPs provide essential health benefits (such as inpatient, outpatient, and preventative care), follow established limits on cost sharing (deductibles, copayments, and out-of-pocket maximum amounts), and meet other requirements. PLWH benefit from the access to the full range of care with controlled costs of premiums and cost shares.

The expanded access to Medicaid that followed the passage of the ACA is also helpful for PLWH. Of people receiving medications on the Virginia ADAP, about $70 \%$ are below $138 \%$ of the Federal Poverty Level (FPL), the qualifying level for expanded Medicaid. ${ }^{7}$ Most ADAP patients would have been covered if Medicaid expansion had been adopted by all states. ${ }^{5}$ The most recent numbers report that 20,000 previous ADAP clients now have Medicaid and 48,000 ADAP clients are covered by QHPs. ${ }^{8}$ For Medicaid, viral suppression rates have been reported in the $65 \%-68 \%$ range, while the viral suppression rate for Medicare and private insurance has been reported at $78 \%-80 \% .^{9,10}$ Importantly, the viral suppression rates for PLWH who obtain care at Ryan White-funded clinics is $72.6 \%$ for all attendees and $77.7 \%$ among those who are retained in care. ${ }^{9}$ Specifically looking at those who are uninsured, the viral suppression rate is $39 \%$ without Ryan White care and $77 \%$ with Ryan White care assistance. ${ }^{10}$

The outcomes associated with different healthcare insurance methods (QHPs, Medicaid) after the implementation of the ACA need to be evaluated because achieving the highest rate of viral suppression is optimal for the individual and public health. ${ }^{11-16}$ We have studied the first year of Virginia ADAP's transition from direct medication provision to offering ACA QHP plans. For ADAP clients, who had a viral load in the year before the ACA was available and in the second half of the year after the ACA was implemented, demonstrating a level of engagement in care, we found that the viral suppression rate of those who shifted to QHPs was $84.6 \%$ compared with $78.6 \%$ for those who stayed on Direct ADAP. ${ }^{17}$ More longitudinal and multistate studies will need to be conducted.

Despite the good news about increased insurance coverage, advocacy is needed, related to adequate coverage of HIV medications. There is evidence that some insurance companies are placing HIV medications on higher cost tiers of formularies, and they may only cover selected medications under each medication class. ${ }^{18}$ In addition, some plans mandate the use of mail order pharmacies, which do not always meet the needs of PLWH. Some mail order pharmacies refuse to coordinate payments with ADAPs, and mail order may not be optimal for patients who change addresses, are homeless, or live in households where HIV status is not disclosed.

\section{National Picture of State ADAPs Incorporation of the ACA}

In the recent past, state ADAPs faced financial challenges as federal funds declined, state funds remained flat, demand for their services increased with PLWH living longer, ART treatment eligibility expanded, and the recession caused more PLWH to qualify for this safety net. ${ }^{19}$ Many ADAPs (including Virginia) used cost containment measures, including waitlists, and could not provide ART to all PLWH who qualified. This situation was largely remedied by emergency federal funds and reprogramming of Ryan White funds, but one state ADAP had a waitlist as recent as 2014, and some states have kept cost containment measures in place. ${ }^{6}$

The Health Resources and Services Administration (HRSA) mandates Ryan White grantees (such as states, some cities, and some clinics) to "vigorously pursue" ACA enrollment for patients. ${ }^{20,21}$ HRSA allows states to pay for insurance (including premiums and cost shares), as long as that cost is not greater than paying for medications for an uninsured patient. $^{22,23}$ The QHP formulary must also, at a minimum, include at least one drug in each class of core antiretroviral therapeutics from the Health and Human Services Clinical Guidelines for the Treatment of HIV/AIDS. ${ }^{24}$

In 2013, 44 ADAPs reported funding PCIPs for ADAP clients. $^{25}$ In 2014, when the ACA Health Insurance Marketplace enrollment started, many ADAPs incorporated QHPs into their healthcare delivery model, including 17 of 20 ADAPs in Medicaid nonexpansion states and 26 of 30 ADAPs in Medicaid expansion states. ${ }^{5}$ These ADAPs provided support in different ways, with some setting a capped amount they would pay for plans and cost shares and some operating like Virginia ADAP by covering full costs of premiums, deductibles, and medication copayments.

The result is a patchwork of varying QHP incorporation, types of QHP costs covered, and eligibility for ADAP-funded QHPs (Fig. 1). Ryan White clinics remain the constant in HIV care across the country. In the annual National ADAP Monitoring report, state ADAPs report their incorporation of the ACA. Four state ADAPs in Medicaid nonexpansion states and 14 state ADAPs (including the District of Columbia) in Medicaid expansion states report covering QHP premiums, deductibles, medication copayments, and HIV visit copayments. ${ }^{5}$ However, within this category, knowing the QHP costs covered does not tell the entire picture; there is variation in the financial eligibility ranging from $138 \%$ to $400 \%$ FPL and $101 \%$ to $400 \%$ FPL, and even some aspects for those over $400 \%$ FPL. This group is similar to the next group which reports covering QHP premiums, deductibles, and medication copayments. The group is not listed as covering visit copayments, but, for example, Virginia ADAP uses non-ADAP earmarked Ryan White funds to cover medical visit copayments. This group includes eight state ADAPs in Medicaid nonexpansion states and nine state ADAPs in Medicaid expansion states. In this group, there is more financial eligibility variation ranging from under $250 \%$ FPL to over $400 \%$ FPL. Five state ADAPs in Medicaid nonexpansion states and four in Medicaid expansion states offered lower levels of QHP component coverage with one only offering to cover medication copayments. Seven state ADAPs reported no incorporation of the ACA or declined to answer the questions. ${ }^{5}$ Despite state ADAPs reporting QHP incorporation information to the National Alliance for State $\&$ Territorial AIDS Directors (NASTAD), it is unclear if and how this information has been disseminated to those on the front lines of HIV care and what guidance and support is being provided for clinics and clients.

\section{Virginia ADAP's Incorporation of the ACA}

With the HRSA mandate, Virginia ADAP decided to pay the full costs of the QHP premiums on behalf of the patients 


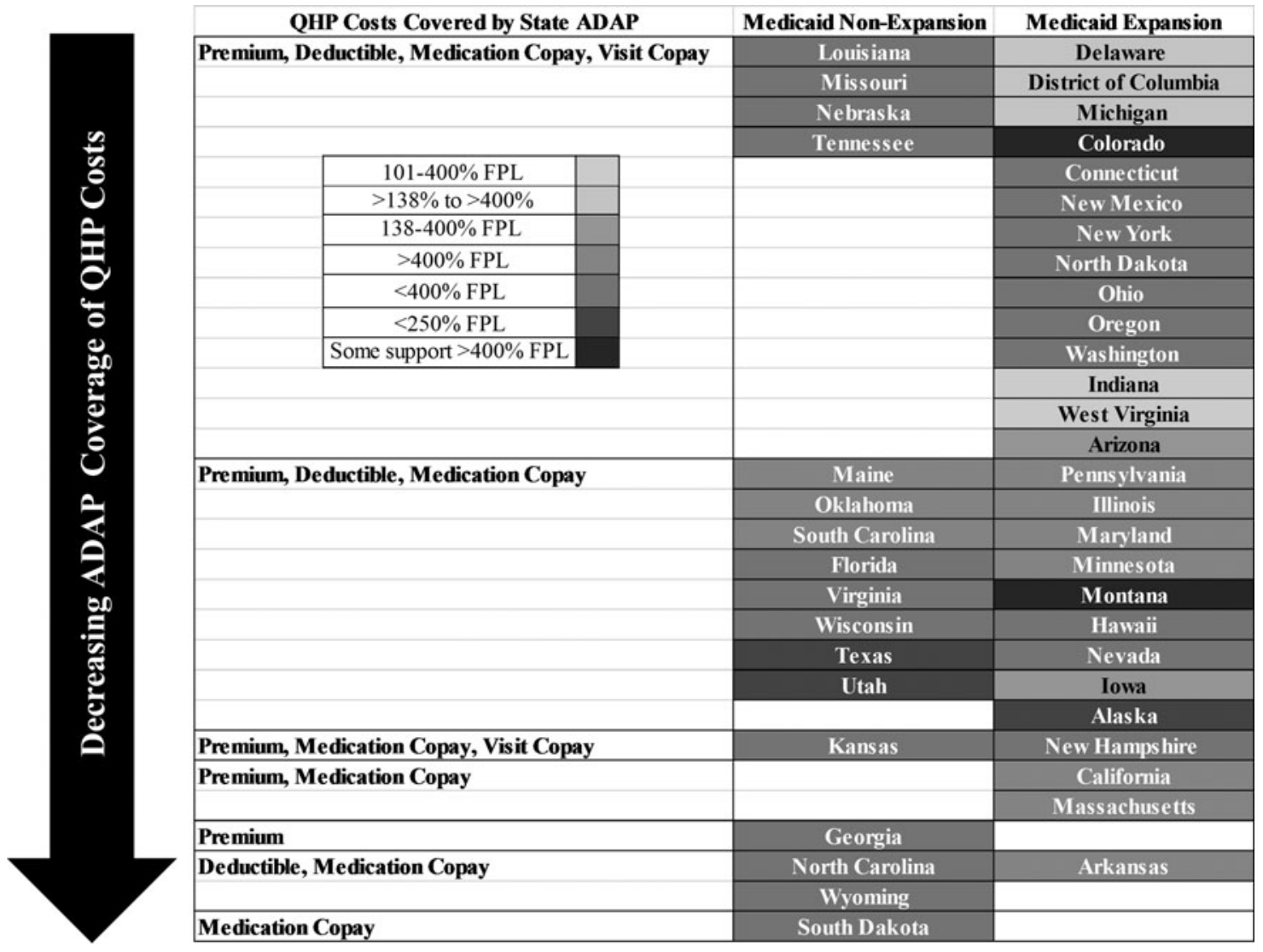

FIG. 1. State AIDS Drug Assistance Programs' (ADAPs) varying incorporation of the Affordable Care Act (ACA). State ADAPs have incorporated the ACA in varying ways resulting in a patchwork of Qualified Health Plan (QHP) incorporation, types of QHP costs covered, and eligibility for ADAP-funded QHPs. The state ADAPs are arranged in decreasing order of QHP cost coverage (from premiums, deductibles, medication copayments, and HIV visit copayments to medication copayments only) and within those categories by least strict income eligibility to most strict ( $>400 \%$ Federal Poverty Level $[$ FPL] to $<250 \%$ FPL). Medicaid nonexpansion states and Medicaid expansion states are separated into two columns.

and the full costs of medication cost shares (deductibles and copayments). The state provides other Ryan White funds to contractors to cover the costs for medical visit and laboratory cost shares for HIV-related care. Virginia ADAP analyzes the costs and the formularies of the available ACA plans before the enrollment period. Virginia submits documentation to HRSA every year, which demonstrates that paying for insurance costs with Ryan White funds is less expensive than directly paying only for medications for uninsured patients. Virginia ADAP was fortunate that it did not face some of the barriers from insurance companies that Louisiana ADAP faced when insurance companies refused to accept ADAP premium payments to support the purchase of QHPs for PLWH. ${ }^{26}$

Annual out-of-pocket cost shares are primarily met through the cost of the HIV medications (paid by Virginia ADAP) within about 3-5 months. Therefore, patients have little, if any, cost share to pay on their own, but have full access to care offered under their QHP. Insured patients also have access to a wide variety of HIV and non-HIV-related care, including preventative and inpatient services.

During the first two ACA enrollment periods, Virginia ADAP paid for silver plans for patients who were between $101 \%$ and $250 \%$ FPL, as they have the largest federal tax credits (for premiums and cost shares) that lower the cost of insurance since the credits can be applied to reduce the cost of the premiums. Patients who are $251 \%-400 \%$ FPL receive smaller federal tax credits toward premiums, and ADAP covered bronze plans (less expensive than silver) for them. Those under $100 \%$ FPL receive no federal tax credits, as the ACA, as originally written, expanded Medicaid to all persons under $138 \%$ FPL. Virginia ADAP paid for bronze plans for them as well.

In 2013, 2,310 Virginia ADAP clients decided to change their ADAP plan from Direct ADAP to a Health Insurance Marketplace Assistance Plan. The majority (64.1\%) were under $100 \%$ FPL, 30.2\% were within 101\%-250\% FPL, and $5.6 \%$ were $251 \%-400 \%$ FPL (Table 1 ). Virginia ADAP pays an average of $\$ 5,399$ per patient annually to keep patients insured under a QHP. This is about half of what it costs $(\$ 10,224)$ to pay for medications for uninsured ADAP patients under Direct ADAP (provides medications only). This annual cost for insurance is further reduced by rebates from pharmaceutical companies. ADAPs receive special rebates when they use funds to pay for medications through insurance plans. Those rebates can represent millions of dollars depending on how many patients are served. Rebates have allowed Virginia to purchase insurance and medications for all ADAP-eligible clients presenting for services, and are a significant resource that prevents the reimplementation of an ADAP waitlist. 
Table 1. Key Financial Numbers in Virginia AiDS Drug Assistance Program's Incorporation of the AfFordable Care Act

\begin{tabular}{|c|c|c|c|c|c|c|c|}
\hline$F P L$ & $\begin{array}{c}\text { No. of ADAP } \\
\text { clients with } Q H P \\
\text { coverage, n }(\%)\end{array}$ & $\begin{array}{l}\text { Average } \\
\text { premium }\end{array}$ & $\begin{array}{c}\text { Annual out } \\
\text { of pocket } \\
\text { cost }\end{array}$ & $\begin{array}{c}\text { Average month } \\
\text { by which cost } \\
\text { share is met }\end{array}$ & $\begin{array}{l}\text { Average } \\
\text { total cost }\end{array}$ & Rebates & $\begin{array}{c}\text { Annual total } \\
\text { cost after } \\
\text { rebate }\end{array}$ \\
\hline All & 2310 & $\$ 3,188$ & $\$ 5,728$ & April & $\$ 8,915$ & $\$ 3,516$ & $\$ 5,399$ \\
\hline$\leq 100 \%^{a}$ & $1482(64.1)$ & $\$ 3,480$ & $\$ 6,350$ & May & $\$ 9,830$ & $\$ 4,000$ & $\$ 5,830$ \\
\hline $101 \%-250 \%^{\mathrm{b}}$ & $699(30.2)$ & $\$ 2,640$ & $\$ 4,293$ & March & $\$ 6,933$ & $\$ 2,400$ & $\$ 4,533$ \\
\hline $251 \%-400 \%{ }^{\mathrm{c}}$ & $129(5.6)$ & $\$ 2,796$ & $\$ 6,350$ & May & $\$ 9,146$ & $\$ 4,000$ & $\$ 5,146$ \\
\hline
\end{tabular}

This table highlights the average ACA insurance premium, annual out-of-pocket cost, average month by which cost share is met, average total cost, average rebates, and annual total cost after rebate. The values are reported for the Virginia ADAP and for the following FPL categories: $\leq 100 \%$ FPL, $101 \%-250 \%$ FPL, and $251 \%-400 \%$ FPL.

${ }^{2}$ People with incomes under 100\% FPL were not eligible for Federal ACA tax credits, but would have been covered by Medicaid if Virginia had elected to expand Medicaid under the ACA.

${ }^{b}$ People with incomes within 101\%-250\% FPL were eligible for Federal ACA tax credits. Within this group, those with incomes $<138 \%$ FPL would have been covered by Medicaid if Virginia had elected to expand Medicaid under the ACA, and those with incomes within $139 \%-250 \%$ FPL would not have been covered.

${ }^{c}$ People with incomes within $251 \%-400 \%$ FPL were eligible for Federal ACA tax credits, but they would not have been covered by Medicaid if Virginia had elected to expand Medicaid under the ACA.

ACA, Affordable Care Act; ADAP, AIDS Drug Assistance Program; FPL, federal poverty level.

While this has been the case in our state, as noted previously, one state ADAP recently had a waitlist and some states have retained cost containment measures. ${ }^{6}$ Adequate federal and state ADAP funding, as well as continuing rebates, are still critical priorities to keeping patients healthy and preventing HIV transmission.

\section{Virginia's ACA Incorporation Best Practices}

Virginia ADAP decided that communication would be a cornerstone of their ACA incorporation. They established a specific communication plan, frequently communicating through weekly stakeholder emails, web postings, and phone calls. They used talking points to improve information consistency. They operated transparently by sharing projections and expenditures and used all existing forums, including community planning groups, planning councils, public hearings, contractors' meetings, and trainings. Another key component of the plan was to participate in statewide roundtables with a wide range of stakeholders, including consumers, medical providers, statewide advocacy groups, pharmaceutical companies and representatives, the Virginia Association of Health Plans, insurance companies, medical center and community health center administrators, ACA Patient Navigator Contractors, and NASTAD.

One challenge with the first enrollment period was that while enrollment began on October 1, 2013, there were glitches with the Healthcare.gov website. Virginia ADAP received delayed plan and formulary information from insurance companies and could not endorse insurance plans as being cost-effective and with appropriate formularies until December 9, 2013. In addition to delaying date of plan endorsement, it also slowed the ability to pay premiums. To avoid this issue in future enrollment periods, Virginia ADAP formed a relationship with Virginia's Bureau of Insurance and gained access to their System for Electronic Rate and Form Filing (SERFF), which provides information needed to assess and understand the insurance products being offered in a state before public release.

During the initial enrollment period, Virginia ADAP needed to determine where to focus efforts. Those on PCIPs at the end of 2013 were prioritized because PCIP plans were scheduled to terminate with QHP implementation. Initial QHP enrollment efforts and a large amount of state funding focused on these clients to avoid gaps in care and ensure continuing insurance coverage in 2014. In addition, clients who were between $101 \%$ and $138 \%$ FPL and $139 \%$ and $250 \%$ FPL were prioritized by Virginia Department of Health. These two groups received federal tax credits making them less expensive to insure than those who were between $251 \%$ and $400 \%$ FPL with smaller tax credits or $<100 \%$ FPL with no tax credits. In subsequent enrollment periods, Virginia ADAP does not anticipate that these calculations will play as large a role in determining enrollment priorities, as the majority of efforts will be focused on reenrollment of insured clients.

\section{HIV Clinic's ACA Incorporation Experience}

The University of Virginia (UVa) Ryan White Clinic became a CMS-certified designated organization (CDO). This application process was straightforward and not timeconsuming. Preference for this designation is given to Ryan White-funded agencies. Becoming a CDO allows the clinic/ organization to train and certify certified application counselors (CACs). UVa then used Ryan White funds to hire and train CACs. The staff offered evening/weekend enrollments in an effort to be available at convenient times for patients. They also offered off-site enrollments at libraries, community-based organizations, and AIDS service organizations. Given the rurality of the UVa catchment area and the distance from which patients travel to the clinic, this component was essential. Enrollment support was provided in four different health districts, and UVa also partnered with referral sites in three additional health districts to expand the reach (Fig. 2). For the 2014 and 2015 enrollment periods, UVa has been one of five Virginia HIV clinics with on-site CACs, and for the 2016 enrollment period, there are six HIV clinics with on-site CACs. During both years, less than $20 \%$ of the $31 \mathrm{HIV}$ clinics that serve ADAP clients have offered on-site QHP enrollment. 


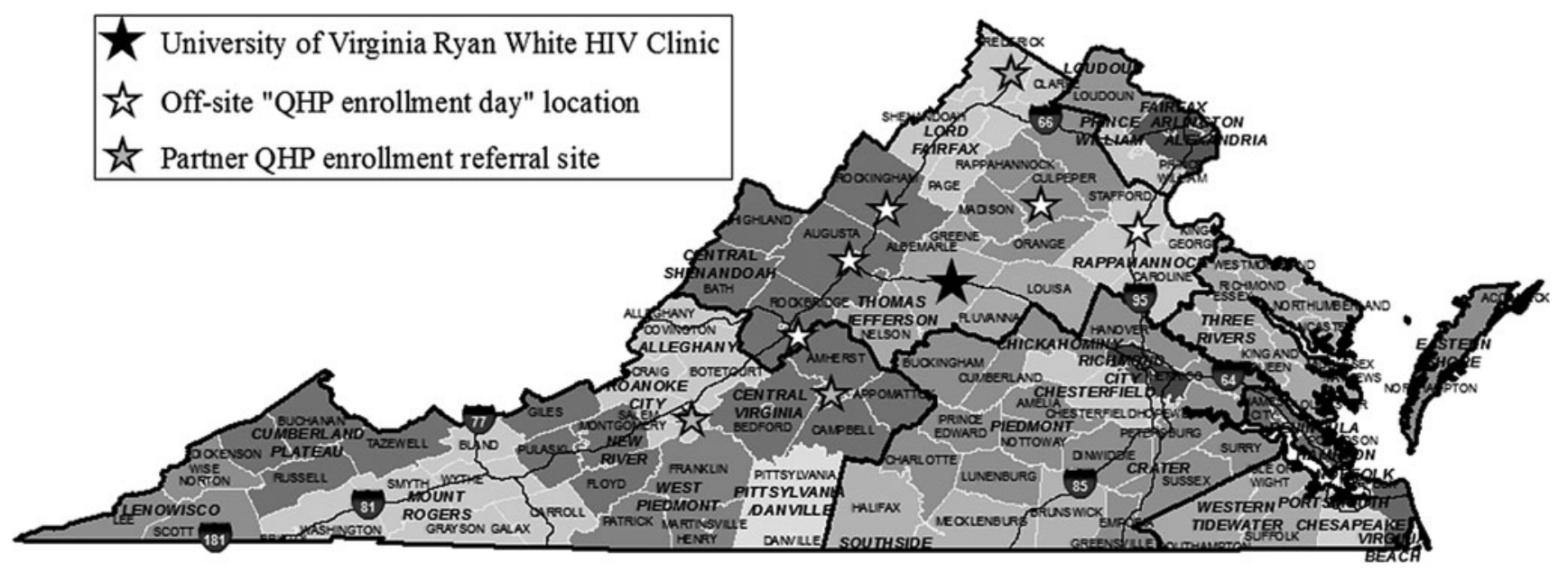

FIG. 2. One HIV clinic's support for ACA QHP Enrollment. The University of Virginia (UVa) Ryan White Clinic became a CMS-certified designated organization and trained and certified application counselors (CACs) who then offered on-site QHP enrollment. UVa CACs also offered off-site enrollments at libraries, community-based organizations, and AIDS service organizations. Enrollment support was provided in four different health districts, and UVa also partnered with referral sites in three additional health districts to expand the reach.

The UVa Ryan White HIV clinic achieved a 2014 QHP enrollment rate of $94 \%$ of actively engaged ADAP clients who were eligible for ADAP-endorsed QHPs. For 2015, the enrollment rate reached $97 \%$. Overall, the clinic saw a decrease in Ryan White expenditures and increased program income from insurance reimbursements. For example, from April 2012 through March 2013, the Ryan White expenditures for laboratories for uninsured patients were $\$ 56,665.11$. By the time period of April 2014 through April 2015, Ryan White expenditures for uninsured patients' laboratories declined by almost $75 \%$ to $\$ 15,074.75$, and, during this time period, insurance reimbursement for laboratories for patients with QHP coverage generated $\$ 157,587.09$ in program income.

\section{HIV Clinic's ACA Best Practices}

As mentioned earlier, Virginia ADAP engaged HIV clinics and clients in their ACA implementation plan. Reaching out to state ADAPs about their current incorporation of the ACA is important. As detailed earlier, many states are reporting that they are incorporating the ACA in some manner. ${ }^{5}$ AIDS advocacy agencies and others may need to advocate for change if a state ADAP's incorporation of the QHPs does not cover enough of the costs associated with insurance to make the QHPs accessible to patients.

Clinics should consider becoming a CDO and having current clinic staff members, such as social workers and case managers, train as CACs. This will allow patients to enroll in QHPs on-site. This ensures that the ADAP client will get counseling for enrollment that is informed by their HIV status, current HIV medications, and ADAP client status. Importantly, being able to enroll at their HIV clinic means that PLWH do not need to disclose their status to external assisters.

If a clinic cannot become a $\mathrm{CDO}$, they can build relationships with $\mathrm{CACs} / \mathrm{Navigators}$ whom they can educate about the specific opportunities for ADAP clients in their state, and they can possibly provide their services on-site.
Local assistance can be found through the Healthcare.gov website by clicking on "Find local help" on the bottom right of the page. To be a resource for patients, clinic staff should become familiar with the QHPs in their area. They need to know which ones include their HIV clinic providers as "innetwork" and research the formularies to assess which ones have best access to first-line ART.

\section{Current Status of Virginia ADAP's ACA Incorporation}

Before 2016 ACA enrollment, Virginia ADAP had about 3,200 QHP-covered ADAP clients and 1,500 ADAP clients who remained on Direct ADAP. For 2016 ACA enrollment, Virginia ADAP assessed that $\sim 1,000$ of the current 1,500 Direct ADAP clients are eligible for ADAP-funded QHPs. This was determined with communication directly with the clients' HIV clinics. Some of these clients were new to ADAP in the last year, and some may have had barriers to previous enrollment in QHPs, including clinic and patientlevel factors. Some possible barriers may be related to retention in care, substance abuse, mental health issues, internet access, transportation, and housing. It is also possible that ADAP client or HIV medical provider views on the ACA affected QHP enrollment of eligible ADAP clients. These 1,000 clients are being targeted in the current enrollment period. In addition, continued ADAP financial stability has resulted in ADAP being able to endorse plans from every metal level (Bronze, Silver, Gold, and Platinum), expanding client choice in plan selection for 2016.

Virginia is an example of how "vigorously pursuing" comprehensive healthcare coverage has led to high levels of QHP coverage for ADAP clients in a Medicaid nonexpansion state and greater program stability. Involvement of stakeholders and prioritizing open and timely communication are two main pillars that have led to this success. Despite comprehensive efforts, there are still uninsured Virginia ADAP clients who are eligible for ADAP-funded QHPs, although some will remain ineligible. 
Whether insured or uninsured, PLWH rely on Ryan White clinics to provide experienced, comprehensive, and quality HIV care. Given high rates of poverty among PLWH and inconsistent expansion of Medicaid, clients will continue to rely on ADAP to assist with QHP-associated costs, such as premiums and cost sharing. As rapid shifts in healthcare delivery for PLWH occur, states should adopt evidencebased strategies that optimize HIV outcomes and costeffectiveness. To do this, continuous assessment of patient outcomes and costs of care associated with states' patchwork approach to ACA incorporation is needed. In addition, continued advocacy for high quality, nondiscriminatory formularies and for strong funding of the Ryan White safety net, including ADAP, is essential.

\section{Acknowledgments}

The authors thank UVa Ryan White Grants Manager Sandy Kelso for the financial clinical data in this article and Lauren Yerkes of VDH for her assistance with Figure 1. This work was supported by the Agency for Healthcare Research and Quality under grant F32HS024196 and the National Institute of Allergy and Infectious Diseases under grant K23AI77339. The content is solely the responsibility of the authors and does not necessarily represent the official views of the Agency for Healthcare Research and Quality.

\section{Author Disclosure Statement}

No competing financial interests exist.

\section{References}

1. Henry J. Kaiser Family Foundation. Key Facts about the Uninsured Population. 2014; Available at: http://kff.org/ uninsured/fact-sheet/key-facts-about-the-uninsured-population/. Accessed September 8, 2015.

2. Centers for Disease Control and Prevention. The Affordable Care Act Helps People Living with HIV/AIDS. 2014; Available at: www.cdc.gov/hiv/statistics/surveillance/terms .html. Accessed September 8, 2015.

3. Goldman DP, Juday T, Linthicum MT, Rosenblatt L, Seekins D: The prospect of a generation free of HIV may be within reach if the right policy decisions are made. Health Aff (Project Hope) 2014;33:428-433.

4. Kates J, Garfield R, Young K, Quinn K, Frazier E, Skarbinski J. Assessing the Impact of the Affordable Care Act on Health Insurance Coverage of People with HIV. 2014; Available at: http://kaiserfamilyfoundation.files.wordpress .com/2013/12/8535-assessing-the-impact-of-the-affordablecare-act-on-health-insurance-coverage.pdf. Accessed September 18, 2015.

5. National Alliance of State \& Territorial AIDS Directors (NASTAD). National ADAP Monitoring Project: 2015 Annual Report. 2015; Available at: www.nastad.org/sites/ default/files/NASTAD-ADAP-Monitoring-Project-AnnualReport-May-2015.pdf. Accessed August 17, 2015.

6. Henry J. Kaiser Family Foundation. AIDS Drug Assistance Programs (ADAPs). 2014; Available at: http:// kff.org/hivaids/fact-sheet/aids-drug-assistance-programs/ \#footnote-106191-2. Accessed November 28, 2014.

7. Virginia State Health Commissioner. AIDS Drug Assistance Program Report. 2014; Available at: http://leg2.state .va.us/dls/h\&sdocs.nsf/37d86b08b5098dd185256eec007a 4359/2755dece7a3bb81485257d070070b882?OpenDocument. Accessed November 1, 2014.

8. National Alliance of State \& Territorial AIDS Directors (NASTAD). ADAP Supports Expanded Access to Care. 2015; Available at: www.nastad.org/sites/default/files/ADAPSupports-Access-to-Care-July-2015.pdf. Accessed September 8, 2015.

9. Doshi RK, Milberg J, Isenberg D, et al.: High rates of retention and viral suppression in United States HIV safety net system: HIV care continuum in the Ryan White HIV/ AIDS program, 2011. Clin Infect Dis 2015;60:117-125.

10. Bradley H, Viall AH, Wortley PM, Dempsey A, Hauck H, Skarbinski J: Ryan white HIV/AIDS program assistance and HIV treatment outcomes. Clin Infect Dis 2016;62:90-98.

11. Cohen MS, Chen YQ, McCauley M, et al.: Prevention of HIV-1 infection with early antiretroviral therapy. N Engl J Med 2011;365:493-505.

12. Castilla J, Del Romero J, Hernando V, Marincovich B, Garcia S, Rodriguez C: Effectiveness of highly active antiretroviral therapy in reducing heterosexual transmission of HIV. J Acquir Immune Defic Syndr 2005;40:96-101.

13. Quinn TC, Wawer MJ, Sewankambo N, et al.: Viral load and heterosexual transmission of human immunodeficiency virus type 1. rakai project study group. N Engl J Med 2000; 342:921-929.

14. Porco TC, Martin JN, Page-Shafer KA, et al.: Decline in HIV infectivity following the introduction of highly active antiretroviral therapy. AIDS (London, England) 2004;18: 81-88.

15. Crawford TN, Sanderson WT, Thornton A: Impact of poor retention in HIV medical care on time to viral load suppression. J Int Assoc Provid AIDS Care 2014;13:242-249.

16. Giordano TP, Gifford AL, White AC, Jr., et al.: Retention in care: A challenge to survival with HIV infection. Clin Infect Dis 2007;44:1493-1499.

17. McManus KA, Rhodes A, Bailey S, et al.: Affordable Care Act Qualified Health Plan Coverage: Association With Improved HIV Viral Suppression for AIDS Drug Assistance Program Clients in a Medicaid Nonexpansion State. Clin Infect Dis 2016 Aug 1;63(3):396-403.

18. Crowley JS, Nevins GR, Thompson M: The americans with disabilities act and HIV/AIDS discrimination: Unfinished business. JAMA 2015;314:227-228.

19. McManus K, Engelhard C, Dillingham R: Current challenges to the united states' AIDS drug assistance program and possible implications of the affordable care act. AIDS Res Treat 2013;2013:Article ID 350169.

20. Public Health Service Act. 42 U.S.C. $\S \S 2605(\mathrm{a})(6)$, 2617(b)(7)(F), 2664(f)(1), and 2671(i) (2012).

21. Health Resources and Services Administration: Ryan white HIV/AIDS program client Eligibility Determinations: Considerations post-implementation of the affordable care act. 2013; Available at: http://hab.hrsa.gov/manageyourgrant/ pinspals/pcn1303eligibilityconsiderations.pdf. Accessed November 21, 2015.

22. Health Resources and Services Administration: Clarifications regarding clients eligible for Private Health insurance and coverage of services by Ryan White HIV/AIDS program. 2013; Available at: http://hab.hrsa.gov/manageyourgrant/ pinspals/pcn1304privateinsurance.pdf. Accessed November 21, 2015.

23. Health Resources and Services Administration: Clarifications regarding use of Ryan White HIV/AIDS program 
funds for premium and cost-sharing assistance for private health insurance. 2014; Available at: http://hab.hrsa.gov/ manageyourgrant/pinspals/pcn1305premiumcostsharing.pdf. Accessed November 21, 2015.

24. Health Resources and Services Administration: Ryan white and the affordable care act frequently asked questions. 2014; Available at: http://hab.hrsa.gov/affordablecareact/faq.pdf. Accessed November 21, 2015.

25. National Alliance of State \& Territorial AIDS Directors (NASTAD), Bowes A, Lefert A, Pund B. National ADAP Monitoring Project Annual Report. 2014; Available at: www.nastad.org/docs/NASTAD\%20National\%20ADAP\% 20Monitoring\%20Project $\% 20$ Annual\%20Report $\% 20-\% 20$ February\%202014.pdf. Accessed September 23, 2014.
26. HIV Health Reform. Breaking- Temporary Restraining Order in Louisiana Insurance Lawsuit. 2014; Available at: www .hivhealthreform.org/2014/02/25/breaking-lambda-legal-filesfederal-lawsuit-against-louisiana-insurers-for-dumping-peoplewith-hiv/. Accessed December 3, 2014.

Address correspondence to: Kathleen A. McManus Division of Infectious Diseases and International Health University of Virginia PO Box 801379 Charlottesville, VA 22908

E-mail: km8jr@hscmail.mcc.virginia.edu 